\title{
Soybean mosaic virus Infection and Helper Component-protease Enhance Accumulation of Bean pod mottle virus-Specific siRNAs
}

\author{
Hyoun-Sub Lim ${ }^{1,2}$, ChanYong Jang ${ }^{1}$, Hanhong Bae ${ }^{3}$, JoonKi Kim ${ }^{1}$, Cheol-Ho Lee ${ }^{4,5}$, Jin-Sung Hong ${ }^{6}$, \\ Ho-Jong Jü ${ }^{7}$, Hong Gi Kim ${ }^{1}$ and Leslie L. Domier ${ }^{2,8 *}$ \\ ${ }^{1}$ Department of Applied Biology, Chungnam National University, Daejeon 305-764, Korea \\ ${ }^{2}$ Department of Crop Sciences, University of Illinois, 1102 Goodwin Avenue, Urbana, IL, 61801, USA \\ ${ }^{3}$ School of Biotechnology, Yeungnam University, 214-1 Dae-dong, Gyeongsan, Korea \\ ${ }^{4}$ Department of Chemical and Biological Engineering, Seokyoung University, Seoul 136-704, Korea \\ ${ }^{5}$ Departments of Plant and Microbial Biology, University of California, Berkeley, 94720, USA \\ ${ }^{6}$ Institute of Natural Sciences, Seoul Woman's University, Seoul 139-774, Korea \\ ${ }^{7}$ Department of Agricultural Biology, Chunbuk National University, Jeonju 561-756, Korea \\ ${ }^{8}$ United States Department of Agriculture-Agricultural Research Service, 1102 South Goodwin Avenue, Urbana, IL 61801, USA \\ (Received on August 30, 2011; Revised on October 17, 2011; Accepted on October 22, 2011)
}

Soybean plants infected with Bean pod mottle virus (BPMV) develop acute symptoms that usually decrease in severity over time. In other plant-virus interactions, this type of symptom recovery has been associated with degradation of viral RNAs by RNA silencing, which is accompanied by the accumulation of virus-derived small interfering RNAs (siRNAs). In this study, changes in the accumulation of BPMV siRNAs were investigated in soybean plants infected with BPMV alone, or infected with both BPMV and Soybean mosaic virus (SMV) and in transgenic soybean plants expressing SMV helper component-protease (HC-Pro). In many potyviruses, HC-Pro is a potent suppressor of RNA silencing. In plants infected with BPMV alone, accumulation of siRNAs was positively correlated with symptom severity and accumulation of BPMV genomic RNAs. Plants infected with both BPMV and SMV and BPMV-infected transgenic soybean plants expressing SMV HC-Pro exhibited severe symptoms characteristic of BPMVSMV synergism, and showed enhanced accumulation of BPMV RNAs and siRNAs compared to plants infected with BPMV alone and nontransgenic plants. Likewise, SMV HC-Pro enhanced the accumulation of siRNAs produced from a silenced green fluorescent protein gene in transient expression assays, while the P19 silencing suppressor of Tomato bushy stunt virus did not. Consistent with the modes of action of HC-Pro in other systems, which have shown that HC-Pro suppresses RNA silencing by preventing the unwinding of duplex siRNAs and inhibiting siRNA methylation, these studies showed that SMV HC-Pro interfered with the activities

\footnotetext{
*Corresponding author.

Phone) +1-217-333-0510, FAX) +1-217-333-9817

E-mail) leslie.domier@ars.usda.gov
}

of RNA-induced silencing complexes, but not the activities of Dicer-like enzymes in antiviral defenses.

Keywords : dicer, posttranscriptional gene silencing, RISC, small interfering RNA

Infection of plants by some viruses produces severe acute symptoms in leaves immediately above inoculated leaves, but symptoms are markedly reduced on upper leaves. This symptom recovery often is accompanied by clearance of virus from asymptomatic leaves and establishment of an antiviral state that prevents reinfection of the upper leaves with closely related viruses (Harrison and Robinson, 2005; Roth et al., 2004). Recovery has been linked to degradation of viral RNAs by post-transcriptional gene silencing (PTGS), an innate antiviral defense system capable of rapid adaptation to different viral pathogens that is found in eukaryotes (Burgyan and Havelda, 2011). While some viruses induce relatively uniform chronic symptoms, others retain irregularly-shaped dark-green areas with low virus titers on infected leaves. Moore et al. (2001) reported that these "green islands" on virus infected leaves, much like recovered leaves, have reduced virus titers because of PTGS of the infecting virus in these regions.

PTGS can be activated by double-stranded (ds) RNA produced during virus infection or by host RNA-directed RNA polymerases from highly abundant single-stranded (ss) RNAs (Pickford and Cogoni, 2003; Tenllado and DiazRuiz, 2001; Tijsterman et al., 2002). Once induced, PTGS results in sequence-specific degradation of targeted RNAs (Tenllado and Diaz-Ruiz, 2001; Voinnet, 2001). This specificity is imparted by short, 21 to $24 \mathrm{nt}$, small interfering RNAs (siRNAs) produced from dsRNA by an 
RNase III-like enzyme called Dicer (Bernstein et al., 2001). siRNAs act as guides in RNA-induced silencing complexes (RISCs) to direct the degradation of viral RNA sequences (Hamilton and Baulcombe, 1999; Hammond et al., 2000; Zamore et al., 2000).

To counteract the restrictive effects of PTGS, many plant viruses express suppressors of RNA silencing that enhance accumulation of virus RNAs by blocking different steps in the PTGS pathway (Baulcombe, 2005; Wang and Metzlaff, 2005). For example, the helper component-protease (HCPro) encoded by many members of the Potyviridae family of plant viruses is a potent suppressor of PTGS that can significantly enhance the pathogenicity of heterologous viruses (Pruss et al., 1997). HC-Pros suppress PTGS by preventing the unwinding of 21-nt ds siRNAs, which prevents their incorporation into functional RISCs (Blevins et al., 2006; Lakatos et al., 2006; Shiboleth et al., 2007; Silhavy et al., 2006; Yu et al., 2006). The P19 protein of Tomato bushy stunt virus (TBSV) suppresses silencing by sequestering 21-nt siRNAs and preventing their incorporation into RISCs (Lakatos et al., 2006; Silhavy et al., 2002). However, some viruses, like Bean pod mottle virus (BPMV), a common viral pathogen of soybean (Giesler et al., 2002), do not express detectable levels of suppressive activities (Gu and Ghabrial, 2005). As a consequence, BPMV titers are high and symptoms are severe early in infection, but virus titers and symptom severity decline as BPMV RNAs are degraded by PTGS. For example, obvious symptoms develop on the first and second trifoliolate leaves above unifoliolate leaves inoculated with BPMV G-7, but third and fourth trifoliolate leaves are almost symptomless (Calvert and Ghabrial, 1983). Reduced symptom severity has been associated with lowered BPMV titers and specific infectivity of the BPMV virion, and preferential degradation of BPMV RNA1 (Calvert and Ghabrial, 1983; Kartaatmadja and Sehgal, 1990). When soybean plants are infected with both BPMV and Soybean mosaic virus (SMV), a member of the Potyviridae, severe symptoms persist throughout the life of the plant (Ross, 1968), and accumulation of BPMV antigens and RNAs increase from 1.3 to 6.1 fold (Anjos et al., 1992; Calvert and Ghabrial, 1983). Similarly, expression of isolated silencing suppressors from SMV (HC-Pro), Turnip crinkle virus (coat protein; CP), or TBSV; P19 in BPMV expression vectors also enhanced BPMV symptom severity (Zhang and Ghabrial, 2006).

As a consequence of PTGS-mediated antiviral defenses, virus-specific siRNAs accumulate in virus-infected plants (Kubota et al., 2003; Van den Boogaart et al., 2004; Xie et al., 2004) Chellappan et al. (2004) reported that recovery in Nicotiana benthamiana plants infected with the geminiviruses African cassava mosaic virus (ACMV) or Sri
Lankan cassava mosaic virus (SLCMV) is preceded by increases in accumulation of virus-specific siRNAs. The opposite phenomenon has been observed with Avocado sunblotch viroid (ASBVd) and Cucurbit leaf crumple virus (CLCV) where accumulation of siRNAs was correlated with levels of viroid or virus genomic DNAs in infected tissues (Hagen et al., 2008; Markarian et al., 2004), but the accumulation of BPMV-derived siRNAs during recovery and mixed infections with SMV has not been investigated.

The effects of viral suppressors of PTGS are not limited to enhancing the accumulation of heterologous viruses. Tobacco etch virus (TEV) HC-Pro has been shown to reverse silencing of ectopically expressed genes in plants (Kasschau and Carrington, 1998; Mallory et al., 2001; Voinnet, 2001), and alter accumulation of microRNAs (miRNAs) that play important roles in cell-fate determination in both plants and animals (Ambros et al., 2003; Hunter and Poethig, 2003). In some studies, P1/HC-Pro reduced accumulation of siRNAs while restoring expression of post-transcriptionally silenced transgenes (Anandalakshmi et al., 1998; Llave et al., 2000; Mallory et al., 2001). For example, TEV P1/HC-Pro suppressed PTGS of a posttranscriptionally silenced green fluorescent protein (GFP) transgene as well as the accumulation of associated siRNAs involved in accumulation of previously undetectable GFP transcripts (Mallory et al., 2002).

In this study, transgenic soybean lines expressing HC-Pro from two different strains of SMV were used to investigate whether symptom recovery in BPMV-infected soybean plants is associated with increased siRNA accumulation, and whether synergism between BPMV and SMV can be attributed to HC-Pro-induced reductions in BPMV siRNAs.

\section{Materials and Methods}

Virus isolates and plants. BPMV isolate 98 used in these studies was collected from an infected soybean plant growing in an Illinois field in 1998, and stored at $-80^{\circ} \mathrm{C}$. SMV strains G2 and G5 were obtained from Dr. John Hill at Iowa State University, and stored at $-80^{\circ} \mathrm{C}$. The production and characterization of transgenic soybean (cv. Jack) lines carrying the uidA gene coding for $\beta$ glucuronidase (GUS) and HC-Pro coding regions of SMV strains G2 and G5 were described previously (Lim et al., 2005). The amino acid sequences of HC-Pros of SMV G2 and G5 differed at 13 of 457 positions. While some research has suggested the existence of functional domains within the HC-Pro protein with the central domain responsible for suppression of RNA silencing (Varrelmann et al., 2007), other research has not supported that hypothesis (TorresBarceló et al., 2008; Wu et al., 2010). Hence, it was not possible to predict the effects of the individual amino acid 
sequence differences on suppression of RNA silencing from their positions alone. Transgenic lines LG2 and LG51 expressed SMV G2 and SMV G5 HC-Pro at levels of $\sim 5 \%$ and $13 \%$, respectively, compared to those detected in SMV G5-infected soybean plants. Neither transgenic line displayed obvious vegetative phenotypes. Seeds of nontransgenic (control) and transgenic T1 soybean lines expressing HC-Pro and GUS were planted in 50:50 soil:Sunshine Mix $^{\mathbb{}}$ (Sun Grow Horticulture, USA) in $10-\mathrm{cm}$ pots in a greenhouse. Plants were arranged in a completely randomized design on greenhouse benches, and grown under a $14 \mathrm{~h}$ photoperiod.

Virus inoculation. Inocula for BPMV and SMV were prepared by grinding symptomatic infected leaves in inoculation buffer $(50 \mathrm{mM}$ sodium phosphate, $\mathrm{pH} 7.0,0.5 \%$ $\mathrm{Na}_{2} \mathrm{SO}_{3}$ ) at a 1:10 (w:v) ratio. Five-day-old unifoliolate leaves were dusted with Carborundum (Fisher Scientific, USA), and rubbed with gauze pads dipped in inoculum. Leaves were recorded as one-day-old when the three leaflets of the trifoliolate leaf were completely separated from each other $(\sim 1 \mathrm{~cm}$ in length).

Quantitative real-time reverse-transcription polymerase chain reaction (qRT-PCR). Whole leaves or leaflets were ground in liquid nitrogen, and total RNA was extracted from $50 \mathrm{mg}$ of ground tissue using Trizol reagent (Invitrogen, USA) according to the manufacturer's recommendation. Copy numbers of BPMV RNA1 and SMV RNA were determined by qRT-PCR using minor groove-binding (MGB) probes designed using Primer Express software (Applied Biosystems, USA). The BPMV probe (5'-TAGAAGGCAGCCAATTG-3') corresponded to nucleotide positions 1915 to 1931 in RNA1, and was labeled with 6carboxyfluorescein at its 5 ' terminus, and a minor groovebinding nonfluorescent quencher at its 3 ' terminus (Applied Biosystem). Flanking primers were selected at positions 1858 (5'-CTCCGAAACAACAGCAGCAA-3') and 1966 (5'-AATTGGAGAAGATGCTGTGTACTCAA-3'). The MGB probe and flanking primers for SMV HC-Pro coding region and procedures for qRT-PCR were described previously (Lim et al., 2005). Copy number standards for BPMV RNA1 and the SMV HC-Pro coding region consisted of nucleotides 621 to 2294 of BPMV RNA1 and nucleotides 1055 to 2780 of the SMV G5 genome inserted into pBluescript KS- (Stratagene, USA). Standard curves were established using a $10^{7}$ range of 10 -fold dilutions of plasmid DNAs.

BPMV RNA and siRNA accumulation over time. To monitor BPMV RNA1 copy numbers in individual leaves at different stages of development, inoculated plants were grown and sampled over 40 days. The first four fullyexpanded trifoliolate leaves were collected when the first trifoliolate was 35 days old and the fourth trifoliolate was 10 days old. To detect BPMV RNA copy numbers in individual leaflets from single trifoliolates, 5-, 15-, and 22day-old individual leaflets of third trifoliolates were collected, and stored at $-80^{\circ} \mathrm{C}$. Total RNA was extracted and used for qRT-PCR analysis and siRNA detection as previously described by Lim et al. (2005). Leaf age was recorded by tagging and dating when trifoliolates of terminal shoot growth were completely separated.

RNA gel blots. RNA preparations enriched in low-molecular-weight RNAs from plants infected with BPMV, SMV, and both BPMV and SMV were prepared as described by Mallory et al. (2003). Leaves of $N$. benthamiana plants were infiltrated with Agrobacterium tumefaciens harboring plasmids pGD:smGFP, expressing a soluble-modified GFP (Davis and Vierstra, 1998), alone or co-infiltrated with pGD:P19, expressing TBSV P19, pGD:HC-Pro, expressing SMV G5 HC-Pro (Lim et al., 2005), or pGD:CP, expressing SMV CP, and fluorescence was detected in epidermal cells by laser scanning confocal microscopy as described by Lim et al. (2010). Low-molecular-weight RNAs from infiltrated $N$. benthamiana leaves and soybean plants were prepared as described (Mallory et al., 2003). Polyacrylamide gels prepared, blotted and hybridized with ${ }^{32} \mathrm{P}$-labeled probes as described by Lim et al. (2005) for soybean samples. For RNA samples from $N$. benthamiana, low molecular weight RNAs specific for the smGFP gene were detected using a non-radioactive DIG probe that was synthesized by PCR using the PCR DIG Probe Synthesis kit (Roche Diagnostics) as described by Goto et al. (2003). Hybridization was detected using the CDP-Star chemiluminescent substrate (Roche Diagnostics).

\section{Results}

BPMV synergism with SMV and transgenic soybean plants expressing SMV HC-Pro. Separately, BPMV 98 and SMV G5 produced mild symptoms on soybean cv. Jack, but plants infected with both viruses exhibited severe stunting along with deformed leaves (Fig. 1). SMV G2 produced much more severe symptoms than SMV G5 on cv. Jack. BPMV-infected LG5-1 transgenic plants had symptoms that were more severe than those observed in BPMV-infected GUS transgenic plants, but less severe than those of plants infected with both BPMV and SMV. When inoculated with BPMV, plants from transgenic line LG2 had more severe symptoms than LG5-1 and comparable to those observed in plants infected with both BPMV and SMV (Fig. 1). As transformed controls, BPMV-infected 


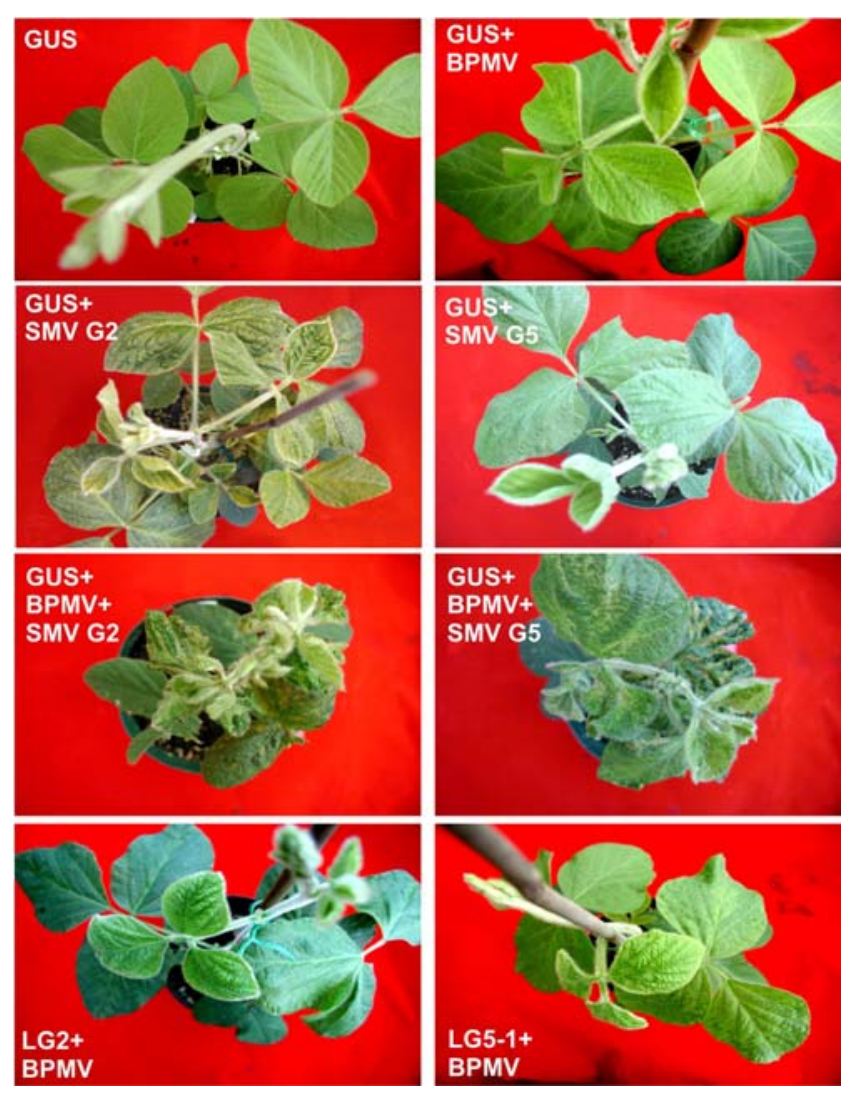

Fig. 1. Symptoms in soybean plants infected with BPMV alone, SMV alone, and BPMV plus SMV at 30 days post inoculation. All plants were inoculated at the unifoliolate stage with the virus(es) indicated and maintained in a greenhouse. GUS: uninfected nontransgenic soybean plant transformed with pCAMBIA1305.1; LG2: transgenic soybean expressing SMV G2 HC-Pro; LG5-1 transgenic soybean expressing SMV G5 HCPro.

GUS transgenic plants exhibited mild symptoms typical of plants infected with BPMV alone at 30 days post inoculation.

qRT-PCR of total RNA from plants infected with BPMV alone showed that BPMV RNA1 abundance decreased from an average of 1.6 copies per pg of total RNA in 10day-old leaves to 0.01 copies per pg of total RNA in 35day-old leaves (Fig. 2A). The abundance of BPMV RNA1 in plants infected with both BPMV and SMV G5 did not differ significantly between 10- and 35-day-old leaves. In 5-, 10-, and 15-day-old leaves, the copy numbers for BPMV RNA1 were not significantly different in plants infected with either BPMV alone or with both viruses. Beginning with 20-day-old leaves, BPMV RNA1 copy numbers decreased in plants infected with BPMV alone. In 35-day-old leaves, BPMV RNA 1 copy numbers were 27.4-fold lower in plants infected with BPMV alone than in plants infected with both BPMV and SMV G5 (Fig. 2A). At this sampling

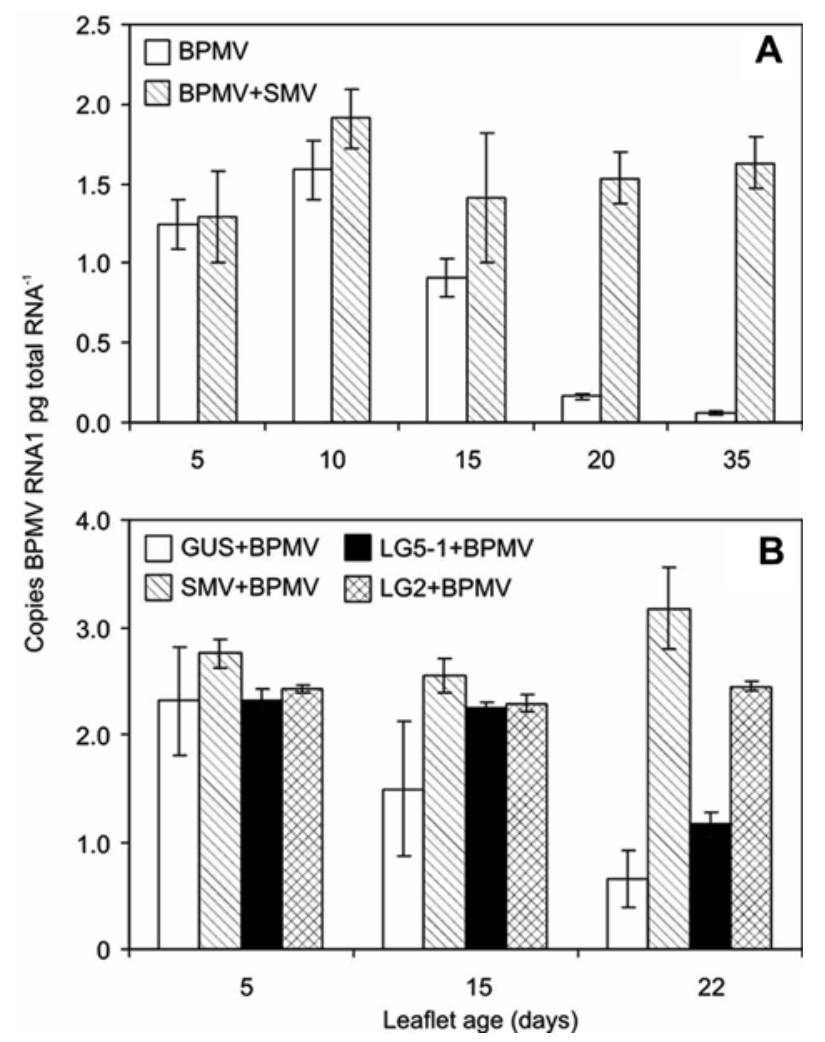

Fig. 2. Accumulation of BPMV RNAl in leaves of plants infected with BPMV alone, plants infected with BPMV and SMV, and transgenic plants expressing SMV HC-Pro. (A) Accumulation of BPMV RNA1 in 5- to 35-day-old trifoliolates of plants infected with BPMV alone, and plants infected with BPMV and SMV G5. (B) Comparison of the accumulation of BPMV RNA1 in individual leaflets from third trifoliolate of nontransgenic plants infected with SMV G5 and transgenic plants expressing GUS, SMV G2 HC Pro (LG2) or SMV G5 HC-Pro (LG5-1). Bars indicate the standard errors of the means of four plants.

date, plants infected with both viruses had more severe symptoms than plants infected with either virus alone (Fig. 1).

When BPMV copy numbers were compared over time among BPMV-infected transgenic lines GUS, LG2, and LG5-1 and nontransgenic soybean plants infected with both BPMV and SMV G5, the accumulation of BPMV RNA1 did not differ significantly in 5- and 15-day-old leaflets (Fig. 2B). Leaflets (22-day-old) of BPMV-infected transgenic lines GUS and LG5-1 (expressed SMV G5 HC-Pro) accumulated significantly less BPMV RNA1 than both non-transgenic soybean plants infected with SMV G5 and plants of LG2 transgenic line expressing SMV G2 HC-Pro. The accumulation of BPMV RNA1 was not reduced significantly over the course of the experiment in non-transgenic soybean plants infected with BPMV and SMV G5 or in BPMV-infected plants of the LG2 transgenic line. 
A

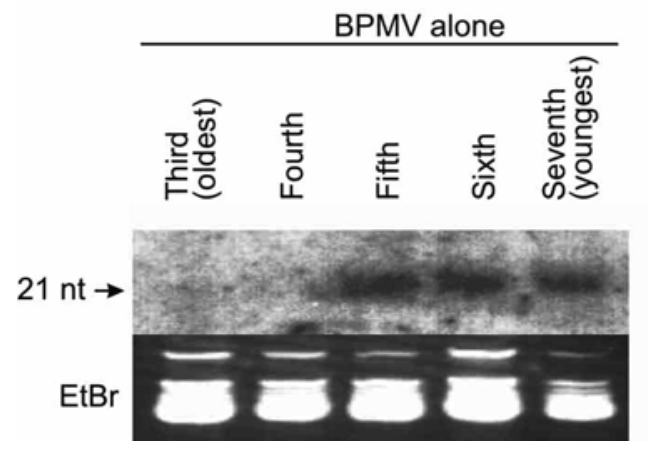

B

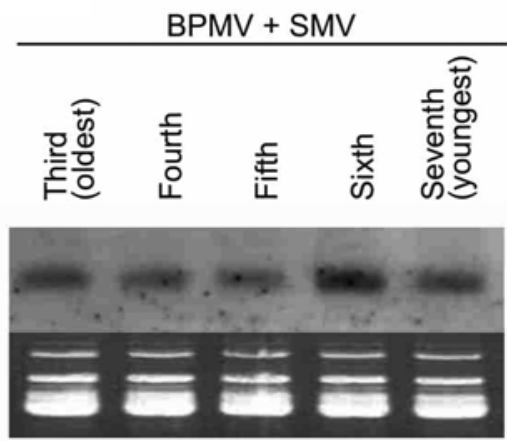

Fig. 3. Accumulation of BPMV-specific siRNAs in leaves in singly- and doubly-infected plants at 30-days-post inoculation. (A) BPMV siRNA accumulation in the third trifoliolate to seventh trifoliolate leaves of BPMV-infected nontransgenic plants. (B) BPMV siRNA accumulation in the third trifoliolate to seventh trifoliolate leaves of nontransgenic plants infected with BPMV and SMV. The migration of a 21-nt DNA oligonucleotide size standard is indicated with an arrow. Ethidium bromide (EtBr) stained gels are shown below autoradiographs as loading controls.

BPMV siRNA accumulation in doubly-infected and BPMV-infected HC-Pro-transgenic plants. When lowmolecular-weight-enriched RNA from transgenic plants infected with BPMV were separated on polyacrylamide gels, blotted to nylon membranes, and hybridized with BPMV-specific probes, siRNAs were detected readily from the third (25-day-old) to the seventh (5-day-old) trifoliolate leaves (Fig. 3). At all sampling dates, the accumulation of BPMV-specific siRNAs paralleled the accumulation of BPMV genomic RNA (Fig. 2) in both singly- and doublyinfected plants (Fig. 3). In the third and fourth trifoliolates, the accumulation of BPMV siRNAs was greatly reduced in plants infected with BPMV alone. However, the levels of

\section{A}
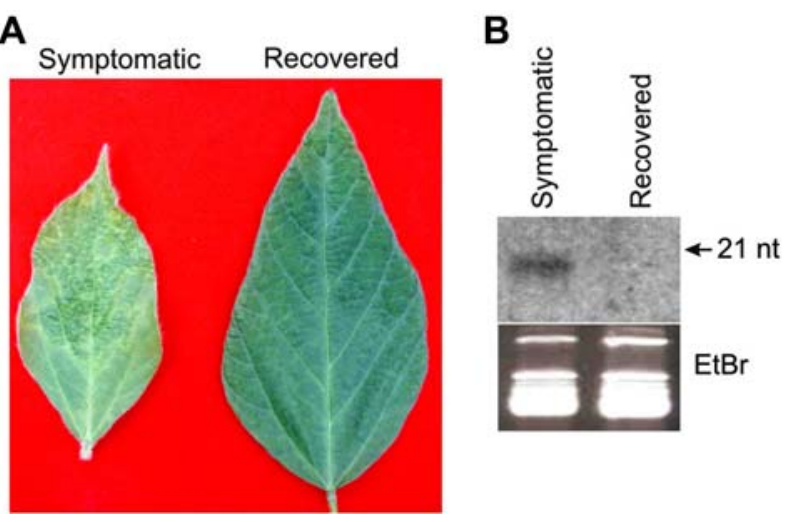

Fig. 4. Accumulation of BPMV siRNAs in symptomatic and recovered soybean leaves. (A) Symptomatic 10-day-old leaflet (left), and symptom recovered 20-day-old leaflet (right). (B) RNA blot of low-molecular-weight-enriched RNAs samples (5 $\mu \mathrm{g})$ extracted from the symptomatic and asymptomatic leaflets. RNAs were separated on polyacrylamide gels, blotted to nylon membranes and hybridized with ${ }^{32} \mathrm{P}$-labeled probes for both BPMV RNA1 and RNA2. The migration of a 21-nt DNA oligonucleotide size standard is indicated. An ethidium bromide $(\mathrm{EtBr})$ stained gel is shown below the blot as a loading control.
BPMV siRNAs in doubly-infected plants remained nearly constant as leaves aged (Fig. 3). In plants infected with BPMV alone, BPMV siRNAs were detected in 10-day-old symptomatic leaves, but not from recovered asymptomatic 20-day-old leaves (Fig. 4).

In fourth trifoliolates, BPMV siRNAs were detected in all singly- and doubly-infected and BPMV-infected HC-Pro transgenic plants (Fig. 5A). In 15-day-old leaflets, LG5-1 accumulated BPMV siRNAs at levels lower than LG2, but at levels higher than plants transformed with GUS alone

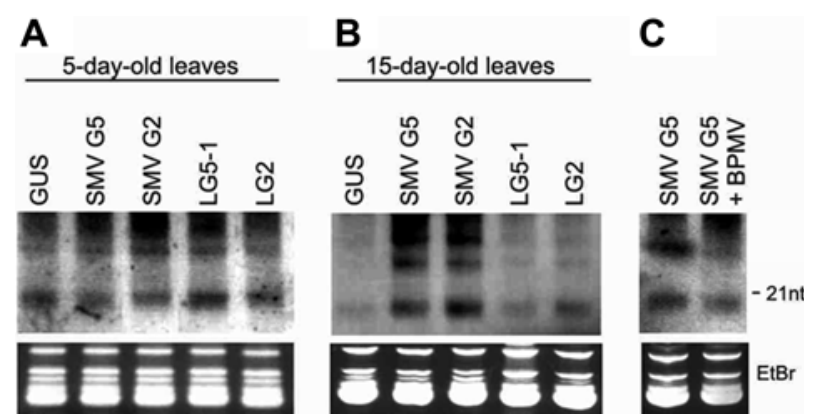

Fig. 5. Accumulation of BPMV and SMV siRNAs in third trifoliolate leaves. Low-molecular-weight-enriched RNA samples were extracted from leaflets of 5 (A) and 15-day-old (B) BPMVinfected third trifoliolates and 15-day-old SMV-infected trifoliolates (C). Five $\mu \mathrm{g}$ RNA were separated on polyacrylamide gels, blotted to nylon membranes and hybridized with ${ }^{32} \mathrm{P}$-labeled probes for both BPMV RNA1 and RNA2 (A and B) or SMV RNA (C). (A and B) All plants were infected with BPMV. In addition two groups of plants were infected with BPMV and SMV G2 or SMV G5. (C) Plants were infected with SMV alone or BPMV and SMV. GUS: uninfected nontransgenic soybean plant transformed with pCAMBIA1305.1; LG2: transgenic soybean expressing SMV G2 HC-Pro; LG5-1 transgenic soybean expressing SMV G5 HC-Pro. The migration of a 21-nt DNA oligonucleotide size standard is indicated. Ethidium bromide (EtBr) stained gels are shown below autoradiographs as loading controls. 
(Fig. 5B). Even though LG2 transgenic plants expressed HC-Pro at lower levels than LG5 plants, LG2 plants accumulated BPMV siRNAs at levels only slightly lower than doubly infected plants in 15-day-old leaflets. Fifteenday-old leaflets of plants infected with BPMV and either SMV strains G2 or G5 accumulated BPMV siRNA levels as high or higher than in 5 day-old leaflets (Fig. 5B). Accumulation of SMV siRNAs was not altered by coinfection with BPMV in 15-day-old leaves (Fig. 5C).

SMV HC-Pro suppressed silencing of smGFP in $N$. benthamiana and enhanced siRNA accumulation. Because HC-Pros have been reported to differentially affect the accumulation of different classes of small RNAs derived from dsRNA and sense ssRNA templates (Chapman et al., 2004; Mallory et al., 2002; Wu et al., 2010), we tested RNA silencing suppression activity of SMV HC-Pro using an Agrobacterium-mediated transient protein expression system in N. benthamiana (Bayne et al., 2005; Johansen and Carrington, 2001). In this assay, $N$. benthamiana leaves were infiltrated with Agrobacterium harboring pGD:smGFP alone or in combination with pGD:HC-Pro, pGD:P19, pGD:CP or the empty pGD vector (Fig. 6A). In leaves coinfiltrated with pGD:smGFP and pGD, low intensity green fluorescence was observed at 2 days after infiltration (Fig.

A

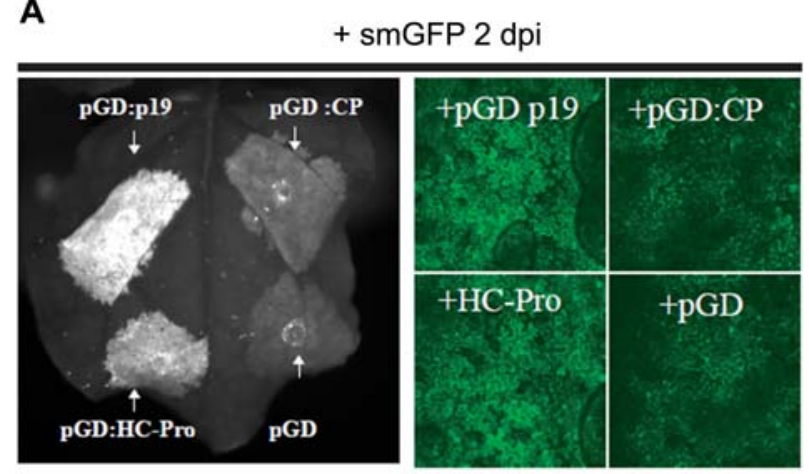

B

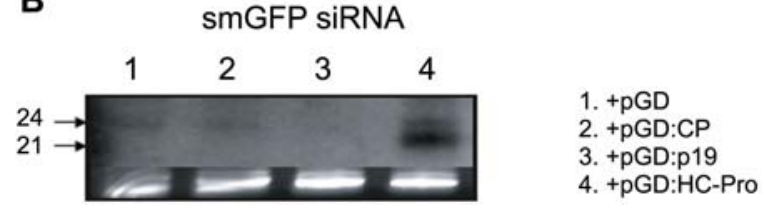

Fig. 6. Agroinfiltration was used for comparing gene silencing suppressor function. (A) pGD:smGFP was co-infiltrated with pGD (empty vector), pGD:P19, pGD:CP and pGD:HC-Pro (left). (B) Confocal-microscope image of agroinfiltrated leaf (right). pGD:smGFP siRNA accumulation: 1, pGD:smGFP alone; 2, pGD:smGFP + pGD:CP; 3, pGD:smGFP + pGD:P19; 4, pGD:smGFP + pGD:HC-Pro. The migration of 21-nt and 24-nt DNA oligonucleotide size standards is indicated by arrows. Ethidium bromide (EtBr) stained gel is shown below as a loading control.
6A); the small bright circular spots present on these and all other infiltrated leaves resulted from autofluorescence of damaged tissue at the sites of infiltration. The intensity of the GFP fluorescence was substantially higher in leaves coinfiltrated with pGD:smGFP and HC-Pro or pGD:smGFP and pGD:P19 (Fig. 6A). GFP fluorescence was not observed in control tissue infiltrated with Agrobacterium containing the pGD vector alone. Suppression of RNA silencing by SMV HC-Pro was similar to results with TBSV P19 (Fig. 6A). We further assessed the HC-Pro-, and P19-infiltrated tissue for the presence of smGFP-derived siRNAs by RNA blot analysis using a probe targeted against smGFP. At 2 days after infiltration, a very low amount of siRNA was present in samples infiltrated with pGD:smGFP alone or pGD:smGFP with pGD:CP (Fig. 6B lanes 1 and 2). However, significantly more smGFP siRNA was present with HC-Pro (Fig. 6B, lane 3). Similar to results reported by Silhavy et al. (2002), no significant accumulation of siRNA was observed when pGD:smGFP was co-infiltrated with TBSV P19 (Fig. 6B). The TBSV P19 protein suppresses RNA silencing by sequestering 21to 24-nt dsRNAs and inhibiting the action of argonaute proteins and production of secondary siRNAs (Silhavy and Burgyan, 2004).

\section{Discussion}

Anjos et al. (1992) and Calvert and Ghabrial (1983) showed that accumulation of BPMV antigen and RNA was about seven-fold higher in third trifoliolates at 22 days after inoculation in soybean plants infected with BPMV and SMV compared to plants infected with BPMV alone. Their findings were confirmed in this study using QRT-PCR to quantify changes in BPMV RNA1 levels at different times after infection and developmental stages. Even though BPMV titers were enhanced in doubly-infected plants, the results showed that the primary role of SMV in BPMVSMV synergism was to stabilize BPMV titers. BPMV RNA1 copy numbers in young-emerging leaves were similar from plants infected with BPMV alone and plants infected with both BPMV and SMV. In doubly-infected plants, BPMV RNA1 copy numbers remained high at all sampling dates; while, BPMV RNA1 copy numbers in plants infected with BPMV alone decreased by 27-fold as leaves matured. From these results, we concluded that BPMV RNA was degraded faster in leaflets infected with BPMV alone than in doubly-infected leaflets. Kartaatmadja and Sehgal (1990) showed that BPMV virions purified from infected soybean plants at 25 days after inoculation contained partially degraded RNA1 and proteolytically cleaved 24-kDa CP. HC-Pros of Lettuce mosaic virus and Potato virus $Y$ interact with and affect the enzymatic activities of $20 \mathrm{~S}$ proteasome, which are involved in protein and RNA 
turnover (Ballut et al., 2005; Dielen et al., 2010; Jin et al., 2007). The combination of these results with those studies suggest that the turnover of BPMV ribonucleoprotein complexes must be constantly replenished by transcription and translation of BPMV RNAs that is facilitated by the protective action of SMV in doubly-infected plants.

In this study, we also showed that co-infection of plants with BPMV and SMV or inoculation of transgenic soybean plants expressing SMV HC-Pro enhanced the accumulation of both BPMV genomic RNAs and siRNAs and showed typical symptoms of dual infection by BPMV and SMV. Soybean line LG2, expressing HC-Pro of SMV strain G2, showed higher levels of BPMV genomic RNA and siRNA accumulation and more severe symptoms than BPMVinfected LG5-1, which expressed the mRNA encoding HCPro of SMV strain G5 at more than twice the level of LG2 (Lim et al., 2007). Savenkov and Valkonen (2001) developed transgenic $N$. benthamiana plants expressing the Potato virus $A$ (PVA) HC-Pro coding region, and showed that $\mathrm{HC}$ Pro was sufficient to promote synergism between PVA and Potato leaf roll virus (PLRV). In that study and the results reported here, the levels of enhancement of virus titers by transgenic HC-Pro were lower than those observed in doubly-infected plants. This might be attributed to lower levels of HC-Pro expression in transgenic plants than in virus-infected plants. The highest expressing transgenic line only expressed SMV HC-Pro mRNA at about $13 \%$ of that found in young leaves of SMV-infected plants (Lim et al., 2005). It is also possible that $P 1$ is required to fully suppress PTGS or stabilize HC-Pro. While analyzing Potato virus $X$ (PVX) and TEV synergism, Pruss et al. (1997) concluded that TEV HC-Pro was sufficient to produce synergistic responses with $\mathrm{PVX}$, but the entire $\mathrm{P} 1 / \mathrm{HC}$-Pro coding region was required to prolong accumulation of PVX negativesense RNA. Additional studies will need to be conducted to define the role of the SMV P1 protein in the synergism between SMV and BPMV.

In plants infected with BPMV alone, or both BPMV and SMV, or transgenic plants expressing SMV HC-Pro, BPMV symptom severity paralleled BPMV RNA and siRNA accumulation. These results are very similar to those reported for ASBVd and CLCV (Hagen et al., 2008; Markarian et al., 2004). Because BPMV siRNAs continued to accumulate even though PTGS was suppressed, SMV HC-Pro must promote synergism by suppressing PTGS at a step downstream of the production of siRNA from viral dsRNAs by Dicer-like enzymes. This interpretation is consistent with the mode of action of HC-Pro, which in other systems has been shown to suppress PTGS by preventing the unwinding of duplex siRNAs and inhibiting HEN1-dependent methylation of siRNAs thereby preventing their assembly into functional RISCs (Blevins et al., 2006; Lakatos et al., 2006;
Shiboleth et al., 2007; Silhavy et al., 2006; Yu et al., 2006). Overall, these studies showed that SMV HC-Pro interfered with the activity of RISCs in antiviral responses in soybean, but not the activities of Dicer-like enzyme(s).

\section{Acknowledgments}

This work was supported by a grant from the Next-Generation Biogreen 21 Program (PJ008063), Rural Development Administration, Republic of Korea.

\section{References}

Ambros, V., Lee, R. C., Lavanway, A., Williams, P. T. and Jewell, D. 2003. MicroRNAs and other tiny endogenous RNAs in $C$. elegans. Curr. Biol. 13:807-818.

Anandalakshmi, R., Pruss, G. J., Ge, X., Marathe, R., Mallory, A. C., Smith, T. H. and Vance, V. B. 1998. A viral suppressor of gene silencing in plants. Proc. Natl. Acad. Sci. USA 95:1307913084.

Anjos, J. R., Jarlfors, U. and Ghabrial, S. A. 1992. Soybean mosaic potyvirus enhances the titer of two comoviruses in dually infected soybean plants. Phytopathology 82:1022-1027.

Ballut, L., Drucker, M., Pugniere, M., Cambon, F., Blanc, S., Roquet, F., Candresse, T., Schmid, H. P., Nicolas, P., Gall, O. L. and Badaoui, S. 2005. HC-Pro, a multifunctional protein encoded by a plant RNA virus, targets the $20 \mathrm{~S}$ proteasome and affects its enzymic activities. J. Gen. Virol. 86:2595-2603.

Baulcombe, D. 2005. RNA silencing. Trends Biochem. Sci. 30:290-293.

Bayne, E. H., Rakitina, D. V., Morozov, S. Y. and Baulcombe, D. C. 2005. Cell-to-cell movement of Potato Potexvirus $X$ is dependent on suppression of RNA silencing. Plant J. 44:471482.

Bernstein, E., Caudy, A. A., Hammond, S. M. and Hannon, G. J. 2001. Role for a bidentate ribonuclease in the initiation step of RNA interference. Nature 409:363-366.

Blevins, T., Rajeswaran, R., Shivaprasad, P. V., Beknazariants, D., Si-Ammour, A., Park, H. S., Vazquez, F., Robertson, D., Meins, F., Jr., Hohn, T. and Pooggin, M. M. 2006. Four plant Dicers mediate viral small RNA biogenesis and DNA virus induced silencing. Nucleic Acids Res. 34:6233-6246.

Burgyan, J. and Havelda, Z. 2011. Viral suppressors of RNA silencing. Trends Plant Sci. 16:265-272.

Calvert, L. A. and Ghabrial, S. A. 1983. Enhancement by soybean mosaic virus of bean pod mottle virus titer in doubly infected soybean Glycine max. Phytopathology 73:992-997.

Chapman, E. J., Prokhnevsky, A. I., Gopinath, K., Dolja, V. V. and Carrington, J. C. 2004. Viral RNA silencing suppressors inhibit the microRNA pathway at an intermediate step. Genes Dev. 18:1179-1186.

Chellappan, P., Vanitharani, R. and Fauquet, C. M. 2004. Short interfering RNA accumulation correlates with host recovery in DNA virus-infected hosts, and gene silencing targets specific viral sequences. J. Virol. 78:7465-7477. 
Davis, S. J. and Vierstra, R. D. 1998. Soluble, highly fluorescent variants of green fluorescent protein (GFP) for use in higher plants. Plant Mol. Biol. 36:521-528.

Dielen, A. S., Badaoui, S., Candresse, T. and German-Retana, S. 2010. The ubiquitin/26S proteasome system in plant-pathogen interactions: a never-ending hide-and-seek game. Mol. Plant Pathol. 11:293-308.

Giesler, L. J., Ghabrial, S. A., Hunt, T. G. and Hill, J. H. 2002. Bean pod mottle virus: a threat to U.S. soybean production. Plant Dis. 86:1280-1289.

Goto, K., Kanazawa, A., Kusaba, M. and Masuta, C. 2003. A simple and rapid method to detect plant siRNAs using nonradioactive probes. Plant Mol. Biol. Rep. 21:51-58.

$\mathrm{Gu}, \mathrm{H}$. and Ghabrial, S. A. 2005. The Bean pod mottle virus proteinase cofactor and putative helicase are symptom severity determinants. Virology 333:271-283.

Hagen, C., Rojas, M. R., Kon, T. and Gilbertson, R. L. 2008. Recovery from Cucurbit leaf crumple virus (Family Geminiviridae, genus Begomovirus) infection is an adaptive antiviral response associated with changes in viral small RNAs. Phytopathology 98:1029-1037.

Hamilton, A. J. and Baulcombe, D. C. 1999. A species of small antisense RNA in posttranscriptional gene silencing in plants. Science 286:950-952.

Hammond, S. M., Bernstein, E., Beach, D. and Hannon, G. J. 2000. An RNA-directed nuclease mediates post-transcriptional gene silencing in Drosophila cells. Nature 404:293-296.

Harrison, B. D. and Robinson, D. J. 2005. Another quarter century of great progress in understanding the biological properties of plant viruses. Ann. Appl. Biol. 146:15-37.

Hunter, C. and Poethig, R. S. 2003. miSSING LINKS: miRNAs and plant development. Curr. Opin. Genet. Dev. 13:372-378.

Jin, Y., Ma, D., Dong, J., Jin, J., Li, D., Deng, C. and Wang, T. 2007. HC-Pro protein of Potato virus $Y$ can interact with three Arabidopsis 20S proteasome subunits in planta. J. Virol. 81:12881-12888.

Johansen, L. K. and Carrington, J. C. 2001. Silencing on the spot. Induction and suppression of RNA silencing in the Agrobacterium-mediated transient expression system. Plant Physiol. 126:930-938

Kartaatmadja, S. and Sehgal, O. P. 1990. Decline of bean pod mottle virus specific infectivity in vivo correlates with degradation of encapsidated RNA-1. Phytopathology 80:11821189.

Kasschau, K. D. and Carrington, J. C. 1998. A counterdefensive strategy of plant viruses: suppression of posttranscriptional gene silencing. Cell 95:461-470.

Kubota, K., Tsuda, S., Tamai, A. and Meshi, T. 2003. Tomato mosaic virus replication protein suppresses virus-targeted posttranscriptional gene silencing. J. Virol. 77:11016-11026.

Lakatos, L., Csorba, T., Pantaleo, V., Chapman, E. J., Carrington, J. C., Liu, Y. P., Dolja, V. V., Calvino, L. F., Lopez-Moya, J. J. and Burgyan, J. 2006. Small RNA binding is a common strategy to suppress RNA silencing by several viral suppressors. EMBO J. 25:2768-2780.

Lim, H. S., Ko, T. S., Hobbs, H. A., Lambert, K. N., Yu, J. M.,
McCoppin, N. K., Korban, S. S., Hartman, G. L. and Domier, L. L. 2007. Soybean mosaic virus helper component-protease alters leaf morphology and reduces seed production in transgenic soybean plants. Phytopathology 97:366-372.

Lim, H. S., Ko, T. S., Lambert, K. N., Kim, H. G., Korban, S. S., Hartman, G. L. and Domier, L. L. 2005. Soybean mosaic virus helper component-protease enhances somatic embryo production and stabilizes transgene expression in soybean. Plant Physiol. Biochem. 43:1014-1021.

Lim, H. S., Vaira, A. M., Reinsel, M. D., Baer, H., Bailey, B. A., Domier, L. L. and Hammond, J. 2010. Pathogenicity of Alternanthera mosaic virus is affected by determinants in RNAdependent RNA polymerase and by reduced efficacy of silencing suppression in a movement-competent TGB1. $J$. Gen. Virol. 91:277-287.

Llave, C., Kasschau, K. D. and Carrington, J. C. 2000. Virusencoded suppressor of posttranscriptional gene silencing targets a maintenance step in the silencing pathway. Proc. Natl. Acad. Sci. USA 97:13401-13406.

Mallory, A. C., Ely, L., Smith, T. H., Marathe, R., Anandalakshmi, R., Fagard, M., Vaucheret, H., Pruss, G., Bowman, L. and Vance, V. B. 2001. HC-Pro suppression of transgene silencing eliminates the small RNAs but not transgene methylation or the mobile signal. Plant Cell 13:571-583.

Mallory, A. C., Mlotshwa, S., Bowman, L. H. and Vance, V. B. 2003. The capacity of transgenic tobacco to send a systemic RNA silencing signal depends on the nature of the inducing transgene locus. Plant J. 35:82-92.

Mallory, A. C., Reinhart, B. J., Bartel, D., Vance, V. B. and Bowman, L. H. 2002. A viral suppressor of RNA silencing differentially regulates the accumulation of short interfering RNAs and micro-RNAs in tobacco. Proc. Natl. Acad. Sci. USA 99:15228-15233.

Markarian, N., Li, H. W., Ding, S. W. and Semancik, J. S. 2004. RNA silencing as related to viroid induced symptom expression. Arch. Virol. 149:397-406.

Moore, C. J., Sutherland, P. W., Forster, R. L. S., Gardner, R. C. and MacDiarmid, R. M. 2001. Dark green islands in plant virus infection are the result of posttranscriptional gene silencing. Mol. Plant-Microbe Interact. 14:939-946.

Pickford, A. S. and Cogoni, C. 2003. RNA-mediated gene silencing. Cell. Mol. Life Sci. 60:871-882.

Pruss, G., Ge, X., Shi, X. M., Carrington, J. C. and Bowman Vance, V. 1997. Plant viral synergism: the potyviral genome encodes a broad-range pathogenicity enhancer that transactivates replication of heterologous viruses. Plant Cell 9:859868.

Ross, J. P. 1968. Effect of single and double infections of soybean mosaic and bean pod mottle viruses on soybean yield and seed characters. Plant Dis. Rep. 52:344-348.

Roth, B. M., Pruss, G. J. and Vance, V. B. 2004. Plant viral suppressors of RNA silencing. Virus Res. 102:97-108.

Savenkov, E. I. and Valkonen, J. P. 2001. Potyviral helper-component proteinase expressed in transgenic plants enhances titers of Potato leaf roll virus but does not alleviate its phloem limitation. Virology 283:285-293. 
Shiboleth, Y. M., Haronsky, E., Leibman, D., Arazi, T., Wassenegger, M., Whitham, S. A., Gaba, V. and Gal-On, A. 2007. The conserved FRNK box in HC-Pro, a plant viral suppressor of gene silencing, is required for small RNA binding and mediates symptom development. J. Virol. 81:13135-13148.

Silhavy, D. and Burgyan, J. 2004. Effects and side-effects of viral RNA silencing suppressors on short RNAs. Trends Plant Sci 9:76-83.

Silhavy, D., Merai, Z., Kerenyi, Z., Kertesz, S., Magna, M. and Lakatos, L. 2006. Double-stranded RNA binding may be a general plant RNA viral strategy to suppress RNA silencing. $J$. Virol. 80:5747-5756.

Silhavy, D., Molnar, A., Lucioli, A., Szittya, G., Hornyik, C., Tavazza, M. and Burgyan, J. 2002. A viral protein suppresses RNA silencing and binds silencing-generated, 21- to 25-nucleotide double-stranded RNAs. EMBO J. 21:3070-3080.

Tenllado, F. and Diaz-Ruiz, J. R. 2001. Double-stranded RNAmediated interference with plant virus infection. J. Virol. 75:12288-12297.

Tijsterman, M., Ketting, R. F. and Plasterk, R. H. 2002. The genetics of RNA silencing. Annu. Rev. Genet. 36:489-519.

Torres-Barceló, C., Martin, S., Daròs, J. A. and Elena, S. F. 2008. From hypo- to hypersuppression: effect of amino acid substitutions on the RNA-silencing suppressor activity of the Tobacco etch potyvirus HC-Pro. Genetics 180:1039-1049.

Van den Boogaart, T., Maule, A. J., Davies, J. W. and Lomonossoff, G. P. 2004. Sources of target specificity associated with the recovery against Pea seed-borne mosaic virus infection mediated by RNA silencing in pea. Mol. Plant Pathol. 5:37-
43.

Varrelmann, M., Maiss, E., Pilot, R. and Palkovics, L. 2007. Use of pentapeptide-insertion scanning mutagenesis for functional mapping of the plum pox virus helper component proteinase suppressor of gene silencing. J. Gen. Virol. 88:1005-1015.

Voinnet, O. 2001. RNA silencing as a plant immune system against viruses. Trends Genet. 17:449-459.

Wang, M. B. and Metzlaff, M. 2005. RNA silencing and antiviral defense in plants. Curr. Opin. Plant Biol. 8:216-222.

Wu, H. W., Lin, S. S., Chen, K. C., Yeh, S. D. and Chua, N. H. 2010. Discriminating mutations of HC-Pro of Zucchini yellow mosaic virus with differential effects on small RNA pathways involved in viral pathogenicity and symptom development. Mol. Plant-Microbe Interact. 23:17-28.

Xie, Z., Johansen, L. K., Gustafson, A. M., Kasschau, K. D., Lellis, A. D., Zilberman, D., Jacobsen, S. E. and Carrington, J. C. 2004. Genetic and functional diversification of small RNA pathways in plants. PLoS. Biol. 2:E104.

Yu, B., Chapman, E. J., Yang, Z., Carrington, J. C. and Chen, X. 2006. Transgenically expressed viral RNA silencing suppressors interfere with microRNA methylation in Arabidopsis. FEBS Lett. 580:3117-3120.

Zamore, P. D., Tuschl, T., Sharp, P. A. and Bartel, D. P. 2000. RNAi: double-stranded RNA directs the ATP-dependent cleavage of mRNA at 21 to 23 nucleotide intervals. Cell 101:25-33.

Zhang, C. and Ghabrial, S. A. 2006. Development of Bean pod mottle virus-based vectors for stable protein expression and sequence-specific virus-induced gene silencing in soybean. Virology 344:401-411. 